\title{
Autism Spectrum Disorder in Cuba: Comprehensive \& Coordinated Response
}

\section{Conner Gorry MA}

"Lola"-her artistic name; she gets upset when people call her by her birth name-wants to be an artist. At every cultural activity, she jumps on stage, takes the microphone, and sings and dances. It makes her mother anxious but she and the other children love it.

Thanks to support from doctors and teachers, laws protecting people with disabilities, and the special education system, Hugo graduated with a technical degree in Library Sciences and today works at a Havana dance company.

Dario was 4 1/2 when he started at the Dora Alonso school. He still used diapers, he couldn't speak or communicate. I didn't believe they could help him; I didn't trust anything or anyone. Now he's transitioning to a regular school and l'm scared, but with help from specialists and other parents, I can face it...l'm counting on my love and understanding to see us through.

"Lola," Hugo and Darío are three young Cubans with autism spectrum disorder (ASD). These children and their families receive multi-disciplinary, individualized treatment, skills and empowerment training, specialized education and advocacy support. Coordinated by the Ministry of Public Health and the Ministry of Education, together with other sectors including culture, sports and the media, the diagnosis, treatment and management of developmental disorders like autism are available throughout Cuba via the country's universal health and education systems.

Challenges abound, however, to guarantee the healthy development of autistic Cubans and the wellbeing of their families and caretakers, while improving awareness and understanding by society at large about this complicated disorder. The most immediate hurdle facing island health authorities is: precisely what is the prevalence of ASD in the country? To date, no national survey has been conducted establishing a baseline for how many people are affected. Without these data, prioritizing programs for this vulnerable population is more difficult, as is resource allocation, defining training needs, and scientific research design. Although all Cubans with disabilities-regardless of origin or type-are protected by law,[1] a total-population study is needed not only to determine the extent of the health problem, but also the implications for Cuban families, the health and education systems, and the national economy. According to $\mathrm{WHO}$, integrating autistic children and adults into society is a priority requiring "actions for making physical, social, and attitudinal environments more accessible, inclusive and supportive."[2] An incomplete evidence base slows progress of these actions, hindering Cuba's goals of social insertion and inclusivity.

\section{Definition, Diagnosis \& Evaluation}

Autism is characterized as a life-long neurodevelopmental disorder for which there is no medical test and there is no cure. Furthermore, the causes are unknown. The fifth edition of the Diagnostic and Statistical Manual of Mental Disorders, published by the American Psychiatric Association and used by Cuban

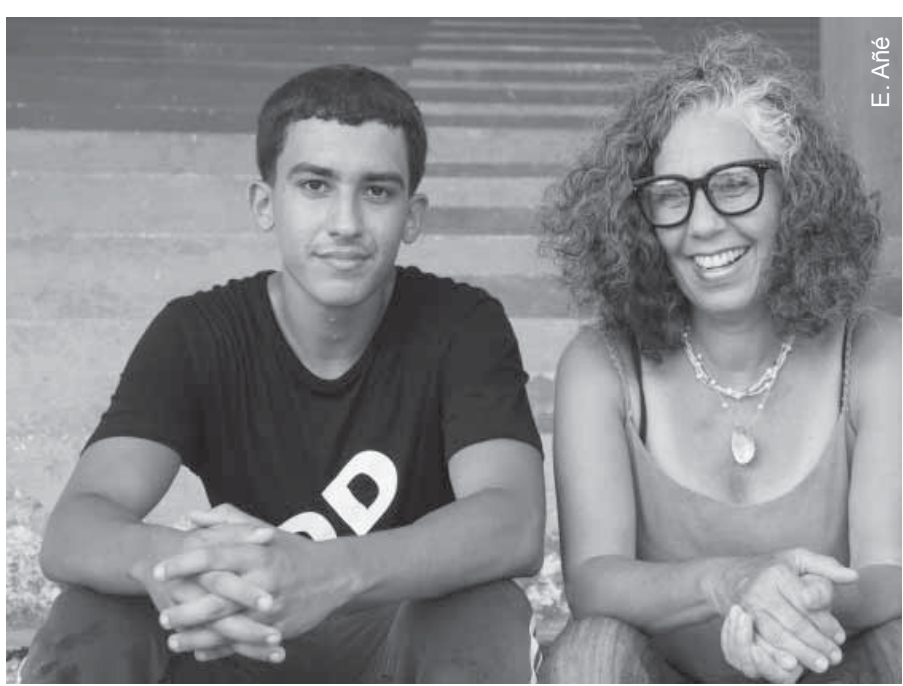

Says Hugo's mom, "I feel blessed to have a son like Hugo; l've learned to love and respect people with differences."

specialists to categorize mental health conditions, defines autistic spectrum disorder (ASD) as "persistent deficits in social communication and social interaction....and restricted, repetitive patterns of behavior, interests, or activities." Diagnostic criteria for ASD are broken down into specific signs and complemented by other parameters including at what age signs and symptoms appeared, if they cause clinically significant impairments in daily functioning and whether they cannot be explained by intellectual disability or global developmental delay.[3]

Designing individualized treatment protocols requires making a differential diagnosis between autism and other developmental disorders and evaluating the severity of the disorder. Severity is categorized according to extent of social communication deficits and the type of restricted, repetitive behaviors exhibited; once these are defined, severity is divided into three levels from the lowest (requires support) to the highest (requires substantial support). Commonly-used metrics of severity include the Childhood Autism Rating Scale, the Autism Diagnostic Interview Revisited, and the Autism Behavior Checklist. Diagnostic tools used to reach a comprehensive evaluation include: direct observation of the child's behavioral patterns and conduct, interviews with parents/guardians and caregivers; hearing and vision screening, and genetic and neurological testing. Any accompanying impairments, genetic or medical conditions, and environmental factors must also be considered when finalizing ASD diagnosis.

No matter where an individual falls on the autistic spectrum, the disorder begins during childhood and usually continues throughout the lifespan. ASD is often detected between 18 months and three years old. The diagnostic process begins when children are observed who have difficulties in verbal and nonverbal communication; show little interest in play or 
interaction with others; exhibit repetitive behaviors; encounter problems switching activities, focus or action, and/or assimilating to change. In Cuba, all children from birth until age 18 receive primary health care from a neighborhood-based medical team-family doctor, family nurse and pediatrician (supplemented by other specialists when indicated). This team conducts regular wellbaby checkups at family doctor-and-nurse offices and makes in-home visits to provide regular developmental surveillance. National guidelines for these visits are: weekly in the baby's first month, office visits every 15 days from 1 to 2 months old, and twice monthly (one in the office, one at the child's home) between 2 and 12 months old. Physical and intellectual development is measured according to national standards that include nutritional guidelines and weight gain, motor skills targets, communication capabilities, and growth rate according to age. Each child's physical and intellectual development is registered on their Infant Health Record, (issued by the hospital where the child was born), and becomes part of their permanent clinical history.[4] Family doctors, together with pediatricians, monitor a child's evolution according to set parameters

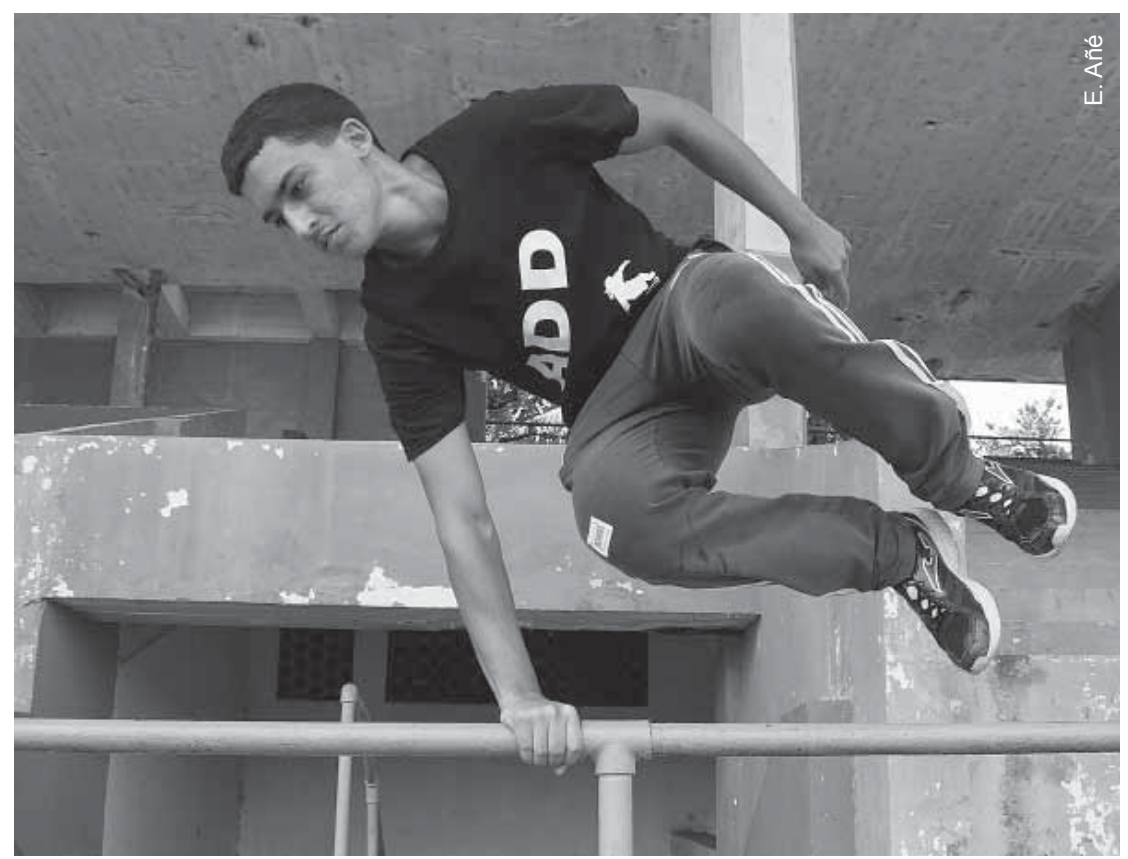

Hugo's passion is parkour, an extreme sport; his dream is to be a personal trainer with his own gym. to allow three levels of classification: satisfactory growth and development, at-risk for delayed development, and identifiable warning signs for delayed development.

It is not unusual for Cuban parents themselves to alert the primary care team to possible autistic signs. "Cuban parents, like most parents, are very attentive to their child's development. When they note a delay in communication or social skills-when their child isn't speaking by a certain age or doesn't respond to their name, for example - they alert their family doctor and pediatrician," explains Dr Mabel Whilby, a child psychiatrist at the Child and Adolescent Mental Health Services of the Cerro Pediatric Teaching Hospital in Havana and coordinator of the Havana Province Child and Adolescent Psychiatry Group. "Almost all potential ASD cases are remitted to us from the primary care team, usually at around 18 months old, prompting specialists to conduct in-depth interviews and apply different methodologies to rule out other developmental delay issues and determine whether the child shows signs of ASD." Dr Whilby notes that it is not solely the psychiatrists at the Child and Adolescent Mental Health Service who make a diagnosis of autism, but rather a multidisciplinary team known as the Diagnostic Commission composed of neurologists, geneticists, psychologists, speech and hearing specialists and educational psychologists. These commissions, headquartered at Orientation and Diagnostic Centers in every municipality across the country, identify the severity of autism, design treatment plans, and recommend educational modalities for the child.

Parents are actively involved throughout this process since a diagnosis of ASD can be devastating to family health and harmony. Dr Cristóbal Martínez, Director of Child and Adolescent Mental Health Services at the Pediatric Teaching Hospital Borrás-Marfán and head of the National Child Psychiatry Group, considers autism "one of the most serious psychiatric conditions because it starts at a very young age and continues through the lifespan, impairing a person's ability to study, work and become an integral part of society." Depending on where a child falls on the autism spectrum, signs and symptoms can become more pronounced with the onset of adolescence when social demands increase, and may be accompanied by depression, anxiety, obsessive behavior and violence. "Autism is a constant in the families' lives, often compromising their members' own health and well-being as they assume very demanding caretaking roles," says Dr Martínez. Specialists have found that when parents learn of a child's autism diagnosis, they typically pass through a cycle beginning with shock, followed by denial, whereupon they seek out second and third opinions. Once the diagnosis is confirmed, they often sink into depression, then start to feel guilty and look to blame someone for their child's condition-usually someone in the family. Specialists say often a terrible sadness sets in before they begin to accept the diagnosis and seek out support. Several services have been developed by Cuban child psychiatrists and educational psychologists to help families accept the diagnosis and learn to manage ASD, such as individual psychotherapy; group therapy with parents, grandparents, and siblings; multi-family therapy designed to promote sharing experiences and knowledge among those facing similar ASD issues; and adaptation, orientation, and information sessions.

Parents' testimonies reflect this process of denial-sadnessacceptance, while recognizing the challenges intrinsic to raising an autistic child. "When Darío was diagnosed with autism, I was depressed, I denied that he needed special education and said, 'No: my son is a beautiful boy, he has no physical impediments, he can attend regular school,"' says Yurien Martínez. Only after multiple orientation sessions with specialists and other parents of autistic children did Yurien begin to accept and embrace her son's condition. For Adelina Hernández, the reaction of her family was difficult: "When Hugo was diagnosed with Asperger syndrome, his grandmother didn't believe it. She didn't want to believe it, so she sought other opinions to learn more." This search introduced the family to people who helped them better understand and manage 
the disorder, transforming doubt into a benefit, says Hugo's mother. "When he was young I felt a terrible burden because some of those around us, including family members, were against how I was raising him. But I followed the specialists' recommendations scrupulously and incorporated what I learned from other families. The child psychiatrists and educational psychologists were wonderful; they showed a lot of compassion for what we faced as a family. I'm so thankful to everyone who helped us on this long, hard, but invigorating road."

\section{Individualized Treatment \& Early Intervention}

ASD is particularly difficult to manage and treat because the causes are unknown and the disorder is often accompanied by comorbidities that may include fragile $X$ syndrome, tuberous sclerosis, epilepsy and attention deficit hyperactivity disorder. Furthermore, signs might not be recognized until later in life, which can further delay accurate diagnosis. What child developmental specialists agree upon, however, is that early detection and intervention are fundamental for improving outcomes. While there is no conclusive scientific evidence as to what causes autism, it is recognized as a neurodevelopmental disorder with genetic and biological components; environmental factors may also increase risk for ASD. Although autism has no cure, symptoms and functionality can improve through a combination of psychosocial interventions, speech therapy, behavioral modification, special education, and alternative and complimentary therapies. In some cases, medication may be prescribed to help improve an autistic person's functionality, control hyperactivity or aggressiveness, increase focus or prevent seizures. Due to the disorder's complexity, there is not a single standardized treatment plan; instead, treatment must be individualized for each patient and adjusted as they age.

In Cuba, individualized treatment is designed by a multidisciplinary team, with review and oversight provided by the Diagnostic Commission in the municipality where the person lives. Interconsultation on and review of treatment plans are provided by the Provincial Child and Adolescent Psychiatry Group (present in each Cuban province). Treatment focuses on early, aggressive intervention and may include: speech and communication therapies; occupational therapies to help children learn how to brush their teeth, use a toilet, dress themselves, etc; and applied behavior analysis. This last is an integrated and individualized treatment protocol designed to modify behavior and increase skillset by using positive reinforcement; a baseline is established for each child measuring their responses to a series of trialsdesired behavioral responses are rewarded, negative or incorrect responses are ignored-and their progress tracked as they improve, with positive reinforcement provided to motivate them to keep striving and learning. Across the country, treatment and follow-up for children with ASD aged 0-19 years are provided at Child and Adolescent Mental Health Centers. Once these patients reach adulthood, they are attended at municipal Departments of Mental Health; all mental health services in Cuba are linked to general and psychiatric hospitals.

Although Cuba has a national strategy utilizing natural and traditional medicine, no complementary or alternative therapies are formally prescribed for treatment of ASD. Nevertheless, there are many types of services available that child psychiatrists may recommend, depending on where patients fall on the autistic continuum. In Havana, there are equine therapy centers which work with autistic children and the dolphin and sea lion trainers at the National Aquarium also have programs for Cuban youth with different types of disabilities and developmental delay. Says Victor Isla, coordinator of the dolphin program at the Aquarium: "Dolphin encounters can be powerful for autistic children. Once there were several children on the platform and the child with autism was alone at the other extreme and the dolphin zipped right to himunprompted by trainers-and spent the entire session playing only with him. Dolphins have a sixth sense about these kidswho just light up during the experience." There are also psychoballet classes, hyperbaric chamber sessions and ozone therapy available for children with ASD, but, cautions Dr Whilby "every child with ASD is different and not everyone improves with these therapies. It's a delicate issue because families are desperate to find something to help their child and may have high expectations. It's important to be realistic with them."

\section{Special Education: One Key to Success}

Determining which educational modality is best suited for each child is an integral part of treatment; education recommendations appropriate to the child's age and clinical picture are made by the Diagnostic Commission. Not all ASD children require special education and the decision is made in close consultation with the parents to find a solution in the best interest of the child's development. Cuba maintains a network of different types of special education modalities across the nation, including schools for children with language impairments, others for those with intellectual disabilities, and seven schools specifically for autistic children-two in Havana, and one each in Santiago de Cuba, Pinar del Río, Cienfuegos, Matanzas, and Holguín Provinces. All children attending special education schools have dedicated buses for their transport-alleviating one more headache in the lives of their parents. ASD children from provinces without a dedicated school for autism matriculate in special education classrooms with teachers trained in methodologies and pedagogies designed for students with developmental disorders. Outside school, these children are attended by the same multidisciplinary team and receive the same mental health services as anyone else suffering from ASD. Some specialized schools and classrooms are designated as 'transitory,' with the specific aim of mainstreaming those children with sufficient socialization skills, behavioral control and intellectual capacity.

"Hugo was 'mainstreamed' when he was eight years old, after spending five years in special education," says Adelina Hernández of her son, who was first diagnosed with language and phonological delay and then intellectual developmental disorder, before finally receiving a diagnosis of Asperger syndrome. "Special education students aren't always well received by their peers in regular schools but his teacher, Elsa, told us 'at this school we work hard so that every child succeeds.' And he did, thanks to her efforts and experience. She was the one who observed that Hugo's attention faltered noticeably after lunch so she developed a study plan where he started early, had classes until noon and then studied at home with me," says Hernández. One of the measures in place to promote success in mainstreaming children with developmental disorders is the role of the transition support teacher, an educator specially trained in teaching ASD students. This teacher visits the classroom where the child is going to study to orient and provide training to the receiving teacher to help smooth transition. 
Not all parents are enthusiastic about mainstreaming however. When "Lola," the future artist, was recommended for mainstreaming, her parents declined, preferring she continue to study at a specialized school. Says Lola's psychiatrist: "the Commission recommended Lola for mainstreaming and although she had some behavioral problems, I personally thought she could succeed. Her parents, however, preferred she remain in the special education system where they felt she was more protected and had specialist teachers." Lola went to primary school at the Dora Alonso School for Autistic Children, founded in 2002; this school, along with the William Soler School for Autistic Children in Santiago de Cuba, was the first established in the country specifically to educate children with ASD. Located among the flowering trees and soaring palms of the Ciudad Libertad in Havana, the Dora Alonso school features small-size classrooms divided by age and severity of their disorder, incorporates standardized pedagogy and methodology such as pictograms, therapy to modify behavior, speech therapy to improve communication, and interactive group activities to encourage socialization. The school has a nurse on staff and a child psychiatrist on site once a week. All teachers at schools for autistic children in Cuba are trained in ASD special education and many have master's or other postgraduate degrees. These teachers have opportunities to participate in training workshops led by Cuban and international specialists to ensure their pedagogy incorporates the latest evidence and methodologies.

Dr Mabel Whilby, the child psychiatrist at the Dora Alonso School, holds consults in a small two-room annex overlooking the playground and gardens (kept tidy and verdant by Julito, an autistic adult who greets visitors when prompted, even though he still has trouble making eye contact). The space is welcoming, with brightly-colored toys, pictures, puzzles, stuffed animals and building blocks in one room, and an array of comfortable chairs in the bigger anteroom. The Diagnostic Commission meets here, convening educational psychologists, psychiatrists, speech therapists, geneticists and neurologists, to evaluate diagnoses and determine the best educational alternatives for each child; new cases may be seen here as well.

"After speaking with you, I'm meeting with a family and their child who has not yet been diagnosed; this is a safe space and it's more relaxing for everyone than a clinical setting," says Dr Whilby. The warm, secure environment it provides parents was one of the motivating factors for a new initiative begun at this school: multi-family therapy. "Periodically we convene parents whose children are enrolled here-during school hours, so they don't have to worry about their children, who are in the care of their teachers, learning and playing-to share their concerns, anxieties, and experiences. We begin with relaxation and stretching exercises and try to create a trusting familial atmosphere where people feel more comfortable sharing." Other services specifically for families include Fresh Air Days, where parents are invited to city parks to spend a day relaxing and not talking about their struggles with autism; therapy for siblings; and orientation and information sessions with grandparents. "Here in Cuba grandparents are active participants in child care and an ASD diagnosis often causes them to suffer-doubly, because they see how it affects their children and their grandchildren," explains Dr Whilby. "Since autism affects the entire family, we try and get everyone involved."

\section{Domestic Research}

\section{\& International Cooperation}

The last half century has seen improvements in surveillance, reporting and diagnosis of $A S D$, contributing to the evidence base and understanding of these disorders. While it's estimated that 1 in 160 children worldwide has an ASD, data for low- and middle-income countries (including Cuba) are either incomplete or nonexistent.[2] The first child psychiatry services were established in Cuba in 1960 at the Calixto García Clinical-Surgical Teaching Hospital and the first case of autism was diagnosed in 1970 at the Borrás-Marfán Pediatric Hospital, both in Havana. More recently, efforts have been made to build collaboration to better understand ASD: in 2000, Cuba hosted its first Child and Adolescent Psychiatry Congress and that same year initiated scientific exchanges and knowledge transfer with the American Academy of Child and Adolescent Psychiatry. Specialists from Brazil, Argentina, the United States and elsewhere have conducted joint research, hosted training workshops and initiated psychosocial community projects in Cuba. Nevertheless, a total-population study to discern the prevalence of ASD in the country has yet to be conductedan important next step according to Cuban specialists. The most current data are from the National Study of Disabilities and Persons with Mental Retardation in Cuba, collected over a 10-month period and concluded in April 2003.[5] While this study collected epidemiologic variables on a national scale related to developmental disorders and delay, its data regarding possible ASD is neither complete nor comprehensive.

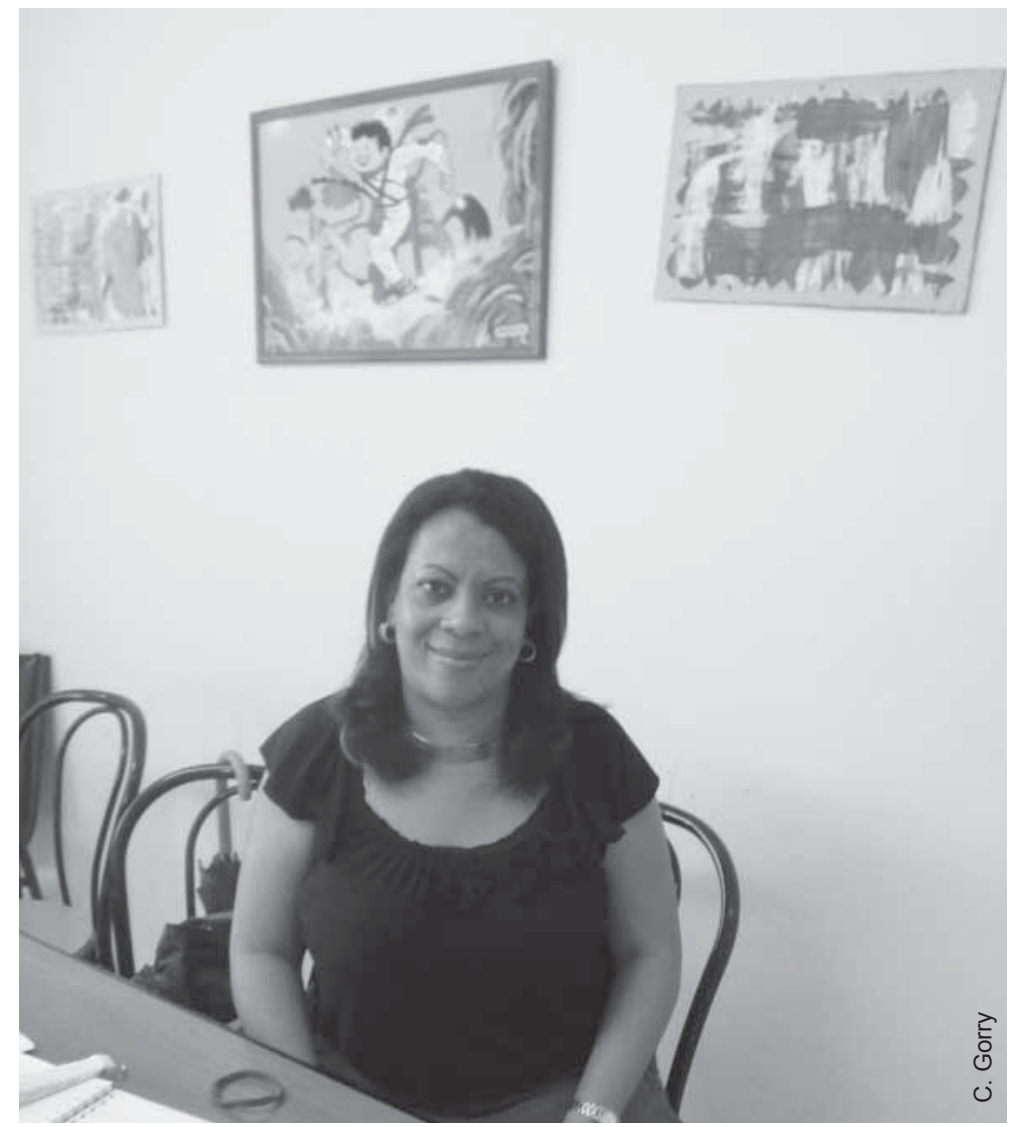

Dr Mabel Whilby, awaiting a consultation with a child and his family at Dora Alonso School for Autistic Children 
Based on these data and records from people receiving autism services and referrals, the Ministry of Public Health estimates that 1 in 2500 Cuban children suffer from ASD-but recognize that this is likely an underestimate due to flawed and incomplete surveillance and data collection methods.[5] In order to develop a reliable evidence base for ASD in Cuba, several research projects are in the pipeline, including a national intellectual disabilities survey among children and adults, which includes specific questions to better detect those showing signs of ASD and a pilot study led by the National Hygiene, Epidemiology and Microbiology Institute in Havana to determine the prevalence of ASD in the Cuban capital; the study is designed to be extended nationally. Collaboration with international colleagues is helping this effort. In 2015, Cuba's Ministry of Public Health invited Autism Speaks, a US-based nonprofit dedicated to public health research, outreach and awareness-building around ASD, to learn about Cuba's surveillance, diagnosis and treatment programs and to provide "guidance in conducting a new study that would provide a more accurate and reliable estimate and, in turn, allow the government to better plan the delivery of autism services."[6] Following this exchange, Cuban specialists were invited by Autism Speaks to their US offices to enhance and extend collaboration.

Another exchange between US and Cuban colleagues provided impetus for a new clinical trial when a US neuropathologist mentioned noninvasive brain stimulation (NIBS) was showing promising preliminary results in improving ASD signs and symptoms. With this lead and a thorough review of the scientific literature, child psychiatrists from the Borrás-Marfán Pediatric Teaching Hospital teamed up with neurophysiologists from the International Neurological Restoration Center (CIREN), both in Havana, to design and conduct clinical trials to test the safety, tolerability and effectiveness of NIBS. These trials are being conducted in strict accordance with national and international ethical standards involving guardians' written informed consent, and adhere to international good clinical practice guidelines.[7]

Dr Belkis Vidal, child psychiatrist and coordinator of the trial says: "The trial started a year ago with eleven children ranging in ages from 5-13 years old. We did the preselection here at the Child and Adolescent Mental Health Services Center of Borrás-Marfán, with collaboration from immunologists, neurophysiologists and speech therapists. The sessions are held at CIREN." Dr Vidal explains that each child receives 20 daily sessions of NIBS, while also continuing their regular ASD treatment. Their clinical diagnosis is closely followed and assessed at 3, 6, 9 and 12 months to measure overall treatment effectiveness. Preliminary results published earlier this year reported all participants improved their autistic symptoms, especially in their social relationships and language and the treatments were found to be both safe and tolerable.[8] Says Dr Vidal, "each child has a different nervous system and doesn't respond identically to the treatment. Though the trial is quite new, we're seeing this type of stimulation does have an effect. And overall, parents with children in the trial are very happy with their progress."

\section{Final Considerations}

Cubans face all manner of life's trials by invoking the popular phrase: "it's not easy," (no es fácil). But their resiliency and determination is reflected in the common rejoinder: "nor is it impossible" (tampoco es imposible). The concerted efforts of Cuban parents, families and people with ASD, together with specialists in health, education and other sectors, are living examples of both refrains. From prime-time soap opera characters with ASD to mainstreaming in schools, there are many innovative, intersectoral initiatives under way to foster acceptance and inclusivity. By teaming up with international collaborators, pursuing neurological and other research, offering alternative therapies and training new specialists in different sectors, Cuba is facing the difficult task of providing a coordinated response and improving outcomes for its autistic population. The neighborhood-based primary care team, national developmental standards and universal, free access to services supports early diagnosis - a key element in effective ASD management. Nevertheless, without a clear picture of ASD burden facing the country and more research among autistic children and adults, designing evidence-based and effective national programs and service provision will remain a challenge. -1 -

\section{References \& Notes}

1. Cubans with disabilities are protected under Chapter VI of the Cuban Constitution (1992, revised 2002), Chapter VIII of the Penal Code, and Article 2 of the Labor Code. Furthermore, Cuba is signatory to the Convention on the Rights of the Child (2000); UN Convention on the Rights of Persons with Disabilities (2007); and UN Universal Declaration on Human Rights (2008), three international instruments recognizing the rights of people with disabilities.

2. World health Organization [Internet]. Geneva: World Health Organization; c2017. WHO Media Center. Factsheets. Autism Spectrum Disorders; 2017 Apr [cited 2017 Jun 10]. Available from: http://www.who.int/mediacentre/factsheets/ autism-spectrum-disorders/en/

3. American Psychiatric Association. Diagnostic and Statistical Manual of Mental Disorders. DSM-5. 5th ed. Virginia: American Psychiatric Publishing. 991 p.

4. Gorry C. Cuba's family doctor-and-nurse teams: a day in the life. MEDICC Rev. 2017 Jan;19(1):6-9.

5. Lantigua Cruz A, Portuondo Sao M, Collazo Mesa T, Lardoeyt Ferrer R. Epidemiology of prenatal genetic and environmental factors of mental retardation in Cuba. MEDICC Rev. 2008 Jan;10(1):29-36.

6. Rosen M. Cuba opens its doors to Autism Speaks [Internet]. New York: Autism Speaks; c2017 [cited 2017 Jun 10]; [about 3 screens]. Available from: https:// www.autismspeaks.org/blog/2015/08/03/cuba-opens-its-doors-autism-speaks

7. Gorry C. The ABCs of clinical trials in Cuba. MEDICC Rev. 2016 Apr;18(3):9-14.

8. Gomez L, Vidal B, Denis M, Marín T, Maragoto C, Vera H, et al. Non-invasive brain stimulation in children with autism spectrum disorder. Brain Stimulation. 2017 Mar-Apr;10(2):346-540. 